\title{
青藏高原地区湖泊正构烷烃有机单体氢同位素 组成及其水文与环境应用
}

刘虎 ${ }^{1,2}$, 杨洪 $^{3}$, 曹蕴宁 ${ }^{1}$, 刘卫国 ${ }^{1,2 *}$

1. 中国科学院地球环境研究所, 黄土与第四纪地质国家重点实验室, 西安 710061;

2. 中国科学院大学, 北京 100049 ;

3. Laboratory for Terrestrial Environments, Department of Science and Technology, College of Arts and Sciences, Bryant University, Smithfield, Rhode Island 02917, USA

* 通讯作者, E-mail: liuwg@loess.1lqg.ac.cn

收稿日期：2017-12-09; 收修改稿日期：2018-02-09; 接受日期：2018-03-01; 网络版发表日期：2018-03-29

国家自然科学基金项目(批准号: 41573005)、国家重点基础研究发展计划项目(编号: 2013CB955901)和中国科学院前沿科学重点研究项目(编 号: QYZDY-SSW-DQC001)资助

摘要湖泊沉积物中正构烷烃氢同位素组成 $(\delta \mathrm{D})$ 广泛应用于古环境变化研究, 但其正构烷烃通常包含多种植物 来源, 使其作为环境和气候指标进行解释时面临许多挑战. 我们系统调查了青藏高原地区15个湖泊中 51 个沉水植 物(包括 39 个眼子菜、 1 个狐尾藻和 11 个川蔓藻), 13 个藻类(包括 5 个轮藻、 3 个刚毛藻和 5 个水绵) 以及 20 个湖边陆 生植物(包括 10 个灌木和 10 个草本植物)正构烷烃的 $\delta \mathrm{D}$ 值. 结果表明: 藻类和沉水植物 $\mathrm{C}_{29}$ 正构烷烃 $\delta \mathrm{D}$ 值与湖水 $\delta \mathrm{D}$ 值显著正相关(藻类: $R^{2}=0.85, p<0.01, n=9$; 沉水植物: $R^{2}=0.90, p<0.01, n=25$ ), 表明这些藻类和沉水植物正构烷烃 的 $\delta \mathrm{D}$ 值反映了湖水 $\delta \mathrm{D}$ 值的变化. 不同种属的藻类和沉水植物, 以及不同水文条件下生长的同一种属植物, 其氢同 位素分馏值 $\left(\varepsilon_{\mathrm{a} / \mathrm{w}}\right)$ 并不稳定, 表明生物合成和环境条件(如盐度)可能会影响藻类和沉水植物的 $\delta \mathrm{D}$ 值. 希里沟湖(封闭 湖) 中川蔓藻的 $\delta \mathrm{D}$ 值显著偏正于其湖边草本植物的 $\delta \mathrm{D}$ 值(one-way ANOVA, $p<0.01$ ), 但可鲁克湖(开放湖) 中的轮藻 植物与其湖边草本植物的 $\delta \mathrm{D}$ 值接近(one-way ANOVA, $p=0.826>0.05$ ), 表明千旱半干旱地区湖泊中藻类和沉水植 物仅在封闭湖记录了湖水相对于大气降水富集 $\delta \mathrm{D}$ 值的信号. 对每一个藻类和沉水植物样品, 不同碳数正构烷烃 $\delta \mathrm{D}$ 值无明显差别，表明结合 $\mathrm{Paq}$ 和平均链长 $(\mathrm{ACL})$ 等指标，不同碳数正构烷烃 $\delta \mathrm{D}$ 值的差值能帮助我们判断沉积物 中正构烷烃的植物来源, 及分析古湖泊盆地的沉积类型(开放沉积或封闭沉积).

关键词正构烷烃, 氢同位素, 沉水植物, 藻类, 青藏高原

\section{1 引言}

青藏高原是世界上海拔最高的高原，平均海拔超
过 $4000 \mathrm{~m}$, 面积约为 $47000 \mathrm{~km}^{2}$, 是对亚洲季风和全球环 境变化敏感区域(An等，2000). 此区域发育有大量湖 泊，利用其湖泊沉积物中多种生物标志化合物进行了

\footnotetext{
中文引用格式: 刘虎, 杨洪, 曹蕴宁, 刘卫国. 2018. 青藏高原地区湖泊正构烷烃有机单体氢同位素组成及其水文与环境应用. 中国科学: 地球科学, 48: 778791, doi: 10.1360/N072017-0253

英文引用格式: Liu H, Yang H, Cao Y N, Liu W G. 2018. Compound-specific $\delta$ D and its hydrological and environmental implication in the lakes on the Tibetan Plateau. Science China Earth Sciences, 61: 765-777, https://doi.org/10.1007/s11430-017-9182-2
} 
大量高分辨率的古环境与古气候变化研究(例如, An 等, 2001; Currie等, 2005; DeCelles等, 2007; Polissar 等, 2009; Henderson等, 2010; Wischnewski等, 2011; He 等, 2013; Wang等, 2013; Zhuang等, 2014; Liu等, 2015, 2017; Li和 Liu, 2017).

正构烷烃作为有机生物标记物，在环境中广泛分 布, 能在环境介质中很好的保存, 是气候变化的可靠 记录(Sessions等，2004; Sachse等，2006; Eglinton和 Eglinton, 2008). 湖泊沉积物中正构烷烃包含多种来 源，包括陆生植物、水生植物、藻类和低等生物等 (Gao等, 2011; Rao等, 2014; Liu和Liu, 2016), 其分子 分布特征常用于区分不同植物来源(Cranwell等, 1987; Ficken等, 2000). 但最近的研究结果表明湖泊沉积物中 长链正构烷烃可能也受沉水植物的影响(Aichner等, 2010a; Liu等, 2015, 2016; Liu和Liu, 2016). 例如, 通过 对青藏高原地区16个湖泊的系统调查, Liu和Liu(2016) 发现藻类长链正构烷烃含量较低(轮藻: $0.6 \mu \mathrm{g} \mathrm{g}^{-1}$ 、刚 毛藻: $0.7 \mu \mathrm{g} \mathrm{g}^{-1}$ 、水绵: $2.4 \mu \mathrm{g} \mathrm{g}^{-1}$ ), 其对湖泊沉积物的 长链正构烷烃的影响可能不大, 但沉水植物, 尤其是眼 子菜和川蔓藻 $\left(\mathrm{C}_{27} \sim \mathrm{C}_{33}\right.$ 含量分别为 46.3 和 $\left.72.7 \mu \mathrm{g} \mathrm{g} \mathrm{g}^{-1}\right)$ 具 有较高的长链正构烷烃含量, 对湖泊中长链正构烷烃 $\mathrm{C}_{27}$ 及 $\mathrm{C}_{29}$ 的贡献不容忽视. 因此, 为了验证这一现象是 否具有普遍性, 我们在青藏高原东北部地区的湖泊中 采集了更多的藻类和沉水植物样品，希望对其正构烷 烃的分布和含量进一步分析.

氢同位素组成是一个有效的古环境变化指标，其 中陆生和水生植物正构烷烃 $\delta \mathrm{D}$ 值分别记录了大气降 水和湖水 $\delta \mathrm{D}$ 值的变化 (Sachse等, 2006; Liu和Yang, 2008; Rao等, 2009; Xie等, 2012; Feakins等, 2016; Liu 等, 2016). 由于水生植物可能对湖泊沉积物中长链正 构烷烃存在较大贡献，充分认识不同种属水生植物 $\delta \mathrm{D}$ 值和 $\varepsilon_{\mathrm{a} / \mathrm{w}}$ 值对准确判断湖泊沉积物中正构烷烃来源, 进 而对准确进行区域古水文条件重建至关重要．Liu等 (2016)对青海湖区域的陆生植物, 水生植物, 沉积物, 湖水和河水的 $\delta \mathrm{D}$ 分析发现, 水生植物 $\delta \mathrm{D}$ 值基本偏正于 此区域的陆生植物, 正构烷烃 $\mathrm{C}_{31}$ 的 $\delta \mathrm{D}$ 值能够有效指示 陆源水文变化, $\Delta \delta \mathrm{D}_{\mathrm{C} 27-31}$ 可用来评价水生植物对湖泊 沉积物中长链正构烷烃的贡献.

在本研究中, 我们系统调查了青藏高原地区湖泊 中常见藻类和沉水植物, 及湖边陆生植物正构烷烃的 分子分布和氢同位素组成. 通过藻类和沉水植物种属
水平上 $\delta \mathrm{D}$ 值的研究, 我们希望进一步认识不同湖泊中 各种属藻类和沉水植物 $\delta \mathrm{D}$ 值和 $\varepsilon_{\mathrm{a} / \mathrm{w}}$ 值的变化特征, 并希 望通过氢同位素组成来区分湖泊沉积物中正构烷烃的 植物来源, 这对准确应用湖泊沉积物正构烷烃 $\delta \mathrm{D}$ 值进 行古气候重建有重要意义.

\section{2 材料与方法}

\section{1 研究区概况与采样}

2013 2016年我们在青藏高原东北部地区 $\left(96^{\circ} 04^{\prime} \mathrm{E}\right.$ $\sim 100^{\circ} 44^{\prime} \mathrm{E}, 33^{\circ} 20^{\prime} \mathrm{N} \sim 37^{\circ} 18^{\prime} \mathrm{N}$ )(图1)的 15 个湖泊中采集 了沉水植物(眼子菜、狐尾藻和川蔓藻), 藻类(轮藻、 刚毛藻和水绵)和湖边陆生植物(包括灌木和草本植 物). 其中, 2015年9月、2016年1月和6月我们在可鲁克 湖、托素湖、德令哈尔海、希里沟湖和洱海采集了一 些样品(包括9个眼子菜、 8 个川蔓藻、 4 个轮藻、6个 刚毛藻、9个水绵、 10 个草本植物和 8 个灌木), 其基本 信息见网络版附表1和2(http://earthcn.scichina.com, 下 同). 我们根据野外调查及前人报道(Qiang等, 2005, 2013, 2014; Zhao C等, 2009, 2010; Zhao Y等, 2007, 2008, 2010; Aichner等, 2010b, 2012; Mischke等, 2010; Tuo等，2011; Wischnewski等，2011; Opitz等，2012; Dietze等, 2013; He等, 2013; Rao等, 2014), 总结了这 些湖泊的基本水文和气候信息(网络版附表3). 其中目 前对一些湖泊，如茶木错、尔拉拉错、金子海、赛永 错、希里沟湖和星星海的研究较少. 此区域为典型的 干旱-半干旱气候, 干燥少雨, 年平均降水量为 100 500mm(Lister等, 1991; Henderson和Holmes, 2009), 植 被以高寒荒漠, 高寒草甸和温带草原为主(Yu等, 2001; Herzschuh等, 2006). 在每个湖泊的不同水深处, 藻类 和沉水植物用抓泥器采上来后用清水洗去表面残余沉 积物, 放在干冰箱进行冷冻保存. 同时采集湖边陆生植 物及每个点位对应湖水样品. 湖水过滤后密封保存到 $100 \mathrm{~mL}$ 小瓶中.

\section{2 正构烷烃提取及 $\delta \mathbf{D}$ 值测定}

取 $0.5 \mathrm{~g}$ 样品用二氯甲烷: 甲醇 $(9: 1)$ 进行超声萃取 $(3 \times 30 \mathrm{~min}, 60 \mathrm{~Hz})$, 合并萃取液后在 $\mathrm{N}_{2}$ 下吹干, 用正己烷 提取3次并转入层析柱(100 200目), 用 $4 \mathrm{~mL}$ 正己烷淋 洗硅胶柱提取正构烷烃. 气相色谱分析在Agilent 


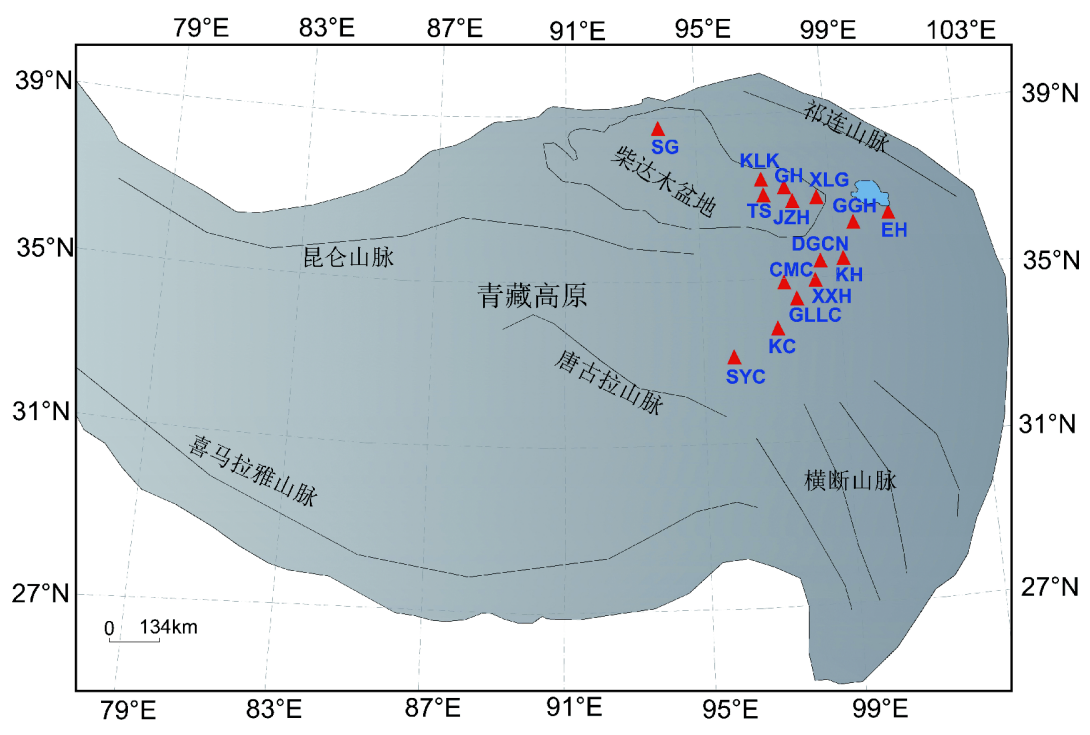

图 1 青藏高原东北部地区藻类和沉水植物采样湖泊

$\mathrm{CMC}$, 茶木错; DGCN, 冬给措纳湖; $\mathrm{EH}$, 洱海; GGH, 更尔海; GH, 德令哈尔海; GLLC, 尔拉拉错; JZH, 金子海; KC, 寇察湖; KH, 苦海; KLK, 可 鲁克湖; SG, 苏干湖; SYC, 赛永错; TS, 托素湖; XLG, 希里沟湖; XXH, 星星海

6890A 气相色谱仪(美国Agilent公司)上进行, 色谱柱为 HP-PLOTQ毛细管柱 $(30 \mathrm{~m} \times 0.32 \mathrm{~mm})$. 氦气作为载气,

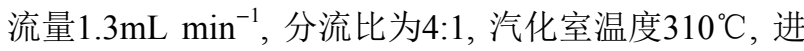
样量 $1 \sim 2 \mu \mathrm{L}$ ，火焰离子检测器(FID)检测(Liu等，2006, $2015,2017)$. 升温程序为: 初始温度 $40^{\circ} \mathrm{C}$ 下保留 $1 \mathrm{~min}$, 然后以 $10^{\circ} \mathrm{C} \min ^{-1}$ 升温至 $150^{\circ} \mathrm{C}$, 再以 $6^{\circ} \mathrm{C} \min ^{-1}$ 升温至 $315^{\circ} \mathrm{C}$, 恒温 $20 \mathrm{~min}$. 在完全相同的条件下对标准物质 (由 $\mathrm{C}_{21} 、 \mathrm{C}_{25} 、 \mathrm{C}_{27} 、 \mathrm{C}_{29} 、 \mathrm{C}_{31} 、 \mathrm{C}_{33}$ 混合而成)进行分析, 通过对样品和标准物质保留时间的对比来确定样品的 烷烃碳数，然后对不同碳数峰面积采用自动积分来确 定不同碳数正构烷烃的相对丰度.

正构烷烃 $\delta$ D值在Delta-V IRMS(Thermo Finnigan) 上测定. 将样品用甲苯定容至 $300 \mathrm{ng} \mu \mathrm{L}^{-1}$, 在不分流 模式下注入进样口, 进样口温度 $280^{\circ} \mathrm{C}$, 其他条件与 $\mathrm{GC}$ 分析一致. 样品经色谱柱分离后, 在高温裂解炉 $1430^{\circ} \mathrm{C}$ 条件下转化为 $\mathrm{H}_{2}$ 气体，进入同位素比值质谱测定氢同 位素值. 测样期间, 每天对仪器进行 $\mathrm{H}_{3}{ }^{+}$因子校正, 并 且每 5 个样品之间加测一个实验室工作标准 (烷烃 $\mathrm{C}_{21} 、 \mathrm{C}_{25} 、 \mathrm{C}_{27} 、 \mathrm{C}_{29} 、 \mathrm{C}_{31}$ 和 $\mathrm{C}_{33}$ 单体化合物 $)$, 以监控实 验过程中 $\delta \mathrm{D}$ 值的重现性和准确性，分析误差 $<3 \%$ (Cao 等, 2012; Liu等, 2012). 所有测定的 $\delta \mathrm{D}$ 值(\%)结果是相 对于Vienna Standard Mean Ocean Water(VSMOW)进行 计算.

\section{3 湖水 $\delta \mathbf{D}$ 值测定}

湖水 $\delta \mathrm{D}$ 值使用 Isotope Water Analyzer(Picarro L2130-i，USA)测定，其 $\delta \mathrm{D}_{\text {water }}$ 值是相对于VSMOW(\%) 进行计算. 为避免记忆效应的影响, 每个样品测 6 次, 后 3 次测定的 $\delta \mathrm{D}$ 值取平均值作为样品 $\delta \mathrm{D}_{\text {water }}$ 值, 测定误差 $<3 \%$. 氢同位素分馏 $\left(\varepsilon_{\mathrm{a} / \mathrm{w}}\right)$ 值计算公式如下:

$$
\varepsilon_{\mathrm{a} / \mathrm{w}}=\left(\frac{\delta \mathrm{D}_{n-\text { alkane }}+1000}{\delta \mathrm{D}_{\text {water }}+1000}-1\right) \times 1000 .
$$

\section{3 结果}

\section{1 藻类、沉水植物和陆生植物正构烷烃含量}

新采集藻类和沉水植物的正构烷烃分布和含量与 我们在此区域已报道的结果(Liu和Liu, 2016)均表明藻 类和沉水植物正构烷烃基本以 $\mathrm{C}_{23}$ 和 $\mathrm{C}_{25}$ 为主峰碳, 但 $\mathrm{C}_{27} \sim \mathrm{C}_{33}$ 一般也具有较高丰度(图2). 眼子菜、川蔓藻、 轮藻、刚毛藻和水绵样品 $\mathrm{C}_{21} \sim \mathrm{C}_{33}$ 正构烷烃中, 其长链 组分 $\left(\mathrm{C}_{27} \sim \mathrm{C}_{33}\right)$ 所占比例分别为 $40 \% 、 33 \% 、 56 \%$ 、 $27 \%$ 和 $61 \%$ (图3). 沉水植物中, 眼子菜和川蔓藻 $\mathrm{C}_{27} \sim \mathrm{C}_{33}$ 正构烷烃含量分别为 72 和 $44 \mu \mathrm{g} \mathrm{g}^{-1}$, 略低于陆生植物 (草本植物平均含量为 $194 \mu \mathrm{g} \mathrm{g}^{-1}$, 灌木平均含量为 $153 \mu \mathrm{g} \mathrm{g}^{-1}$ )(图3). 藻类 $\mathrm{C}_{27} \sim \mathrm{C}_{33}$ 正构烷烃含量基本较低, 
表 1 德令哈尔海、可鲁克湖、苏干湖、托素湖和希里沟湖的湖水 $\delta \mathrm{D}$ 值 ${ }^{\mathrm{a})}$

\begin{tabular}{|c|c|c|c|c|c|c|c|}
\hline 样品号 & 湖泊 & 水深(m) & 湖泊类型 & 水文条件 & 湖水来源 & 采样时间 & 湖水 $\delta \mathrm{D}$ 值 $(\% 0)$ \\
\hline QHW16-7 & $\mathrm{GH}$ & 12 & 咸水湖 & 封闭湖 & 大气降水和地下水 & 2016年6月 & -2.3 \\
\hline QHW16-8 & $\mathrm{GH}$ & 9.4 & 咸水湖 & 封闭湖 & 大气降水和地下水 & 2016年6月 & -2.3 \\
\hline QHW16-9 & $\mathrm{GH}$ & 7.9 & 咸水湖 & 封闭湖 & 大气降水和地下水 & 2016年6月 & -2.5 \\
\hline QHW16-10 & $\mathrm{GH}$ & 5.6 & 咸水湖 & 封闭湖 & 大气降水和地下水 & 2016年6月 & -1.8 \\
\hline QHW16-11 & $\mathrm{GH}$ & 3.7 & 咸水湖 & 封闭湖 & 大气降水和地下水 & 2016年6月 & -1.7 \\
\hline QHW16-12 & $\mathrm{GH}$ & 1.8 & 咸水湖 & 封闭湖 & 大气降水和地下水 & 2016年6月 & -1.9 \\
\hline QHW15-5 & KLK & 5.23 & 淡水湖 & 开放湖 & 大气降水和河水 & 2015年6月 & -39.2 \\
\hline QHW15-6 & KLK & 5 & 淡水湖 & 开放湖 & 大气降水和河水 & 2015年6月 & -37.9 \\
\hline QHW15-7 & KLK & 4.3 & 淡水湖 & 开放湖 & 大气降水和河水 & 2015年6月 & -37.5 \\
\hline QHW15-8 & KLK & 3.7 & 淡水湖 & 开放湖 & 大气降水和河水 & 2015年6月 & -37.4 \\
\hline QHW15-51 & KLK & 4.8 & 淡水湖 & 开放湖 & 大气降水和河水 & 2015年9月 & -37.9 \\
\hline QHW15-52 & KLK & 5.4 & 淡水湖 & 开放湖 & 大气降水和河水 & 2015年9月 & -37.3 \\
\hline QHW15-53 & KLK & 4.9 & 淡水湖 & 开放湖 & 大气降水和河水 & 2015年9月 & -37.2 \\
\hline QHW15-54 & KLK & 3.7 & 淡水湖 & 开放湖 & 大气降水和河水 & 2015年9月 & -37.7 \\
\hline QHW15-57 & SG & 0.8 & 咸水湖 & 封闭湖 & 大气降水和河水 & 2015年9月 & -0.2 \\
\hline QHW15-58 & SG & 0.8 & 咸水湖 & 封闭湖 & 大气降水和河水 & 2015年9月 & -0.8 \\
\hline QHW15-11 & $\mathrm{TS}$ & 15.4 & 咸水湖 & 封闭湖 & 大气降水和河水 & 2015年6月 & 14.2 \\
\hline QHW15-12 & TS & 16.3 & 咸水湖 & 封闭湖 & 大气降水和河水 & 2015年6月 & 15.2 \\
\hline QHW15-13 & TS & 15.7 & 咸水湖 & 封闭湖 & 大气降水和河水 & 2015年6月 & 15.3 \\
\hline QHW15-14 & $\mathrm{TS}$ & 13.1 & 咸水湖 & 封闭湖 & 大气降水和河水 & 2015年6月 & 15.4 \\
\hline QHW15-15 & TS & 6.3 & 咸水湖 & 封闭湖 & 大气降水和河水 & 2015年6月 & 11.1 \\
\hline QHW15-16 & $\mathrm{TS}$ & 3.3 & 咸水湖 & 封闭湖 & 大气降水和河水 & 2015年6月 & 12.9 \\
\hline QHW16-1 & TS & 11.9 & 咸水湖 & 封闭湖 & 大气降水和河水 & 2016年6月 & 11.2 \\
\hline QHW16-2 & TS & 10.2 & 咸水湖 & 封闭湖 & 大气降水和河水 & 2016年6月 & 11.9 \\
\hline QHW16-3 & TS & 8.1 & 咸水湖 & 封闭湖 & 大气降水和河水 & 2016年6月 & 12.2 \\
\hline QHW16-4 & $\mathrm{TS}$ & 5.5 & 咸水湖 & 封闭湖 & 大气降水和河水 & 2016年6月 & 12.5 \\
\hline QHW16-5 & $\mathrm{TS}$ & 3.8 & 咸水湖 & 封闭湖 & 大气降水和河水 & 2016年6月 & 9.3 \\
\hline QHW16-6 & TS & 2.1 & 咸水湖 & 封闭湖 & 大气降水和河水 & 2016年6月 & 11.4 \\
\hline QHW16-16 & XLG & 2 & 咸水湖 & 封闭湖 & 大气降水和河水 & 2016年6月 & -8.8 \\
\hline QHW16-17 & XLG & 1.5 & 咸水湖 & 封闭湖 & 大气降水和河水 & 2016年6月 & -8.8 \\
\hline QHW16-18 & XLG & 1.2 & 咸水湖 & 封闭一湖 & 大气降水和河水 & 2016年6月 & -16.9 \\
\hline
\end{tabular}

a) GH, 德令哈尔海; KLK, 可鲁克湖; SG, 苏干湖; TS, 托素湖; XLG, 希里沟湖

其中轮藻、刚毛藻和水绵平均含量分别为 $1.5 、 1.4$ 和 $3.9 \mu \mathrm{g} \mathrm{g}^{-1}$ (图3).

\section{2 藻类、沉水植物和陆生植物正构烷烃 $\delta \mathbf{D}$ 值}

陆生草本植物正构烷烃 $\delta \mathrm{D}$ 值偏负, 变化范围为 $-213 \sim-185 \%$, 平均值为 $-198 \% \mathrm{o}(n=10)$, 灌木正构烷烃 $\delta \mathrm{D}$ 值偏正, 变化范围为 $-175 \sim-111 \%$, 平均值为
$-145 \% 0(n=10)$ (网络版附表 4$)$. 藻类和沉水植物中, 眼 子菜、狐尾藻和川蔓藻正构烷烃 $\delta \mathrm{D}$ 值变化范围分别 为 $-213 \sim-139 \%$ 、 $-169 \%$ 和 $-165 \sim-142 \%$, 平均值分 别为 $-164 \% \mathrm{o}(n=39) 、-169 \% \mathrm{o}(n=1)$ 和 $-154 \% \mathrm{o}(n=11)$, 轮 藻、刚毛藻和水绵正构烷烃 $\delta \mathrm{D}$ 值变化范围分别为 $-214 \sim-185 \%$ 、 $-141 \sim-136 \%$ 和-169 -135\% , 平均 值分别为 $-198 \% \mathrm{o}(n=5) 、-139 \% \mathrm{o}(n=3)$ 和 $-157 \% \mathrm{o}(n=5)$ 
表 2 青藏高原藻类、沉水植物和陆生植物的 $\varepsilon_{\mathrm{a} / \mathrm{w}}$ 值 ${ }^{\mathrm{a}}$

\begin{tabular}{|c|c|c|c|c|c|c|}
\hline 样品号 & 湖泊 & 植物种属 & 水深 $(\mathrm{m})$ & 源水 $\delta \mathrm{D}$ 值 $(\%)$ & $\mathrm{C}_{29}$ 正构烷伾 $\delta \mathrm{D}$ 值 $(\%)$ & $\varepsilon_{a / \mathrm{w}}$ 值 $(\%)$ \\
\hline \multicolumn{7}{|l|}{ 沉水植物 } \\
\hline QHP15-15-2 & TS & 眼子菜 & 6.3 & 11.1 & -139.8 & -149 \\
\hline QHP15-16-2 & TS & 眼子菜 & 3.3 & 12.9 & -139.3 & -150 \\
\hline QHP16-2-1 & TS & 眼子菜 & 10.2 & 11.9 & -147.3 & -157 \\
\hline QHP16-3-1 & TS & 眼子菜 & 8.1 & 12.2 & -150.3 & -160 \\
\hline QHP16-4-1 & TS & 眼子菜 & 5.5 & 12.5 & -148.9 & -159 \\
\hline QHP16-5-1 & TS & 眼子菜 & 3.8 & 9.3 & -141.7 & -150 \\
\hline QHP15-57 & SG & 眼子菜 & 0.8 & -0.8 & -155.6 & -155 \\
\hline QHP16-16 & XLG & 川蔓藻 & 2 & -8.8 & -158.2 & -151 \\
\hline QHP16-17 & XLG & 川蔓藻 & 1.5 & -8.8 & -159.2 & -152 \\
\hline QHP16-18 & XLG & 川蔓藻 & 1.2 & -16.9 & -164.4 & -150 \\
\hline \multicolumn{7}{|l|}{ 藻类 } \\
\hline QHP15-5 & KLK & 轮藻 & 5.23 & -39.2 & -204.8 & -172 \\
\hline QHP15-7 & KLK & 轮藻 & 4.3 & -37.5 & -214.2 & -184 \\
\hline QHP15-8 & KLK & 轮藻 & 3.7 & -37.4 & -186.8 & -155 \\
\hline QHP15-52 & KLK & 轮藻 & 5.4 & -37.3 & -184.9 & -153 \\
\hline QHP15-13 & TS & 刚毛藻 & 15.7 & 15.3 & -136.2 & -149 \\
\hline QHP15-14 & TS & 刚毛藻 & 13.1 & 15.4 & -140.9 & -154 \\
\hline QHP16-4-2 & TS & 刚毛藻 & 5.5 & 12.5 & -138.6 & -149 \\
\hline QHP15-58 & $\mathrm{SG}$ & 水绵 & 0.8 & -0.8 & -168 & -167 \\
\hline QHP16-11 & $\mathrm{GH}$ & 水绵 & 3.7 & -1.7 & -135.2 & -134 \\
\hline \multicolumn{7}{|l|}{ 陆生植物 } \\
\hline QHP15-35 & KLK & 草本 & & -40.7 & -207 & -173 \\
\hline QHP15-38 & KLK & 草本 & & -40.7 & -191 & -157 \\
\hline QHP15-40 & KLK & 草本 & & -40.7 & -180 & -146 \\
\hline QHP15-42 & KLK & 草本 & & -40.7 & -203 & -169 \\
\hline QHP15-46 & KLK & 草本 & & -40.7 & -209 & -175 \\
\hline QHP15-47 & KLK & 草本 & & -40.7 & -185 & -150 \\
\hline QHP16-13-2 & XLG & 草本 & & -40.7 & -213 & -180 \\
\hline QHP16-14-1 & XLG & 草本 & & -40.7 & -184 & -149 \\
\hline QHP16-14-2 & XLG & 草本 & & -40.7 & -213 & -179 \\
\hline QHP15-34 & KLK & 灌木 & & -40.7 & -111 & -73 \\
\hline QHP15-36 & KLK & 灌木 & & -40.7 & -129 & -92 \\
\hline QHP15-37 & KLK & 灌木 & & -40.7 & -175 & -140 \\
\hline QHP15-39 & KLK & 灌木 & & -40.7 & -158 & -123 \\
\hline QHP15-41 & KLK & 灌木 & & -40.7 & -157 & -122 \\
\hline QHP15-43 & KLK & 灌木 & & -40.7 & -131 & -94 \\
\hline QHP16-13-3 & XLG & 灌木 & & -40.7 & -137 & -101 \\
\hline QHP16-14-3 & XLG & 灌木 & & -40.7 & -161 & -126 \\
\hline
\end{tabular}

a) 青藏高原藻类: 轮藻、刚毛藻和水绵; 沉水植物: 眼子菜、川蔓藻; 陆生植物: 草本、灌木. 大气降水 $\delta \mathrm{D}$ 平均值 $(-40.7 \%)$ 参考Yao等 (2013)和朱建佳等(2015)的报道 

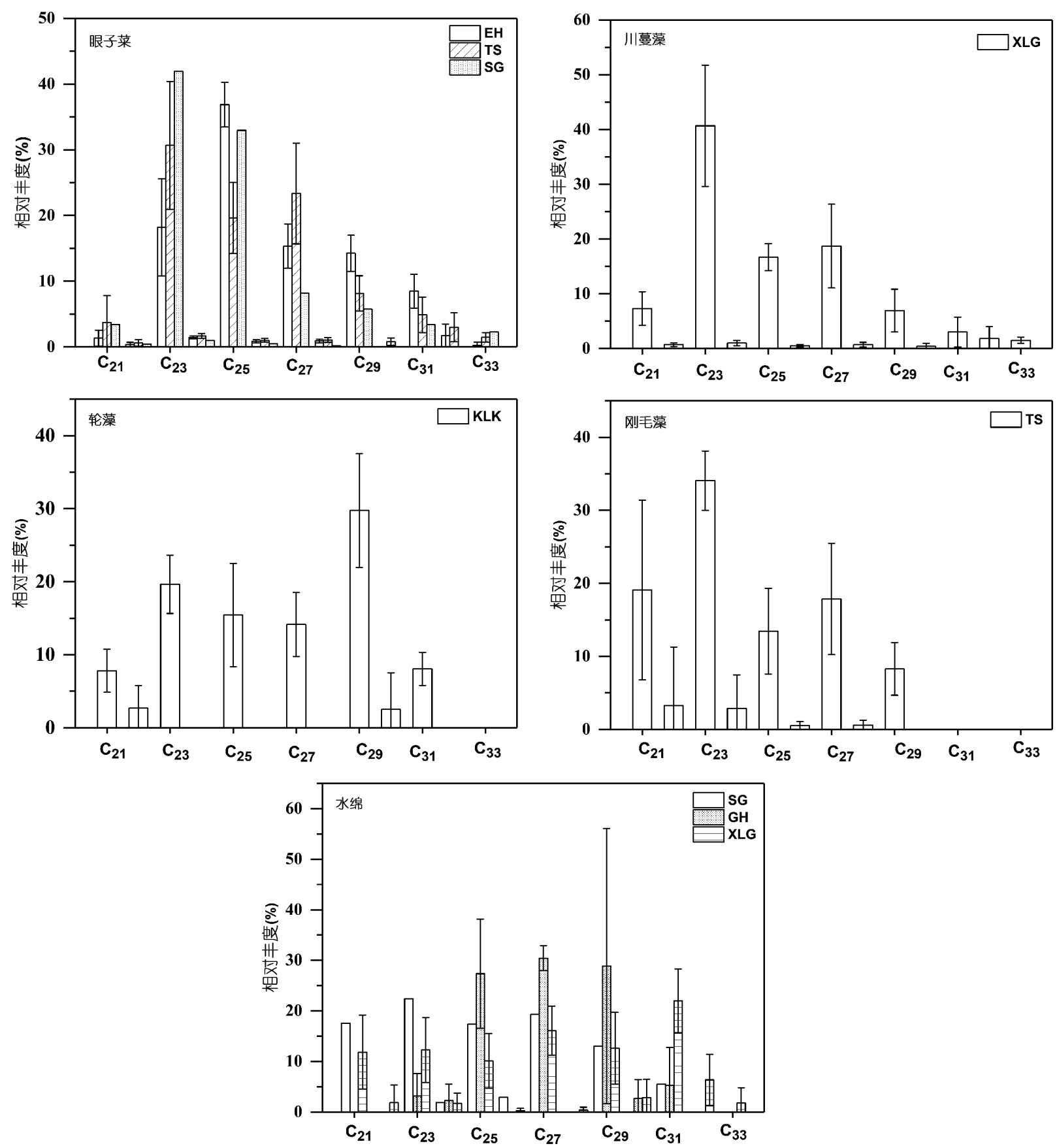

图 2 青藏高原地区湖泊中藻类和沉水植物正构烷烃相对丰度

$\mathrm{EH}$, 洱海; TS, 托素湖; SG, 苏干湖; XLG, 希里沟湖; KLK, 可鲁克湖; GH, 德令哈尔海

(网络版附表4).

\section{3 藻类、沉水植物和陆生植物正构烷烃 $\varepsilon_{\mathrm{a} / \mathrm{w}}$ 值}

为了计算藻类, 沉水植物与湖水之间的 $\varepsilon_{\mathrm{a} / \mathrm{w}}$ 值, 我
们野外采样过程中同时在各采样点采集湖水，测定其 $\delta \mathrm{D}$ 值. 虽然湖水 $\delta \mathrm{D}$ 值可能随着季节不同或年份不同改 变, 但我们发现青藏高原地区的某个特定湖泊在雨季 (6 9月)的湖水 $\delta \mathrm{D}$ 值基本保持稳定(表1). 例如, 可鲁克 


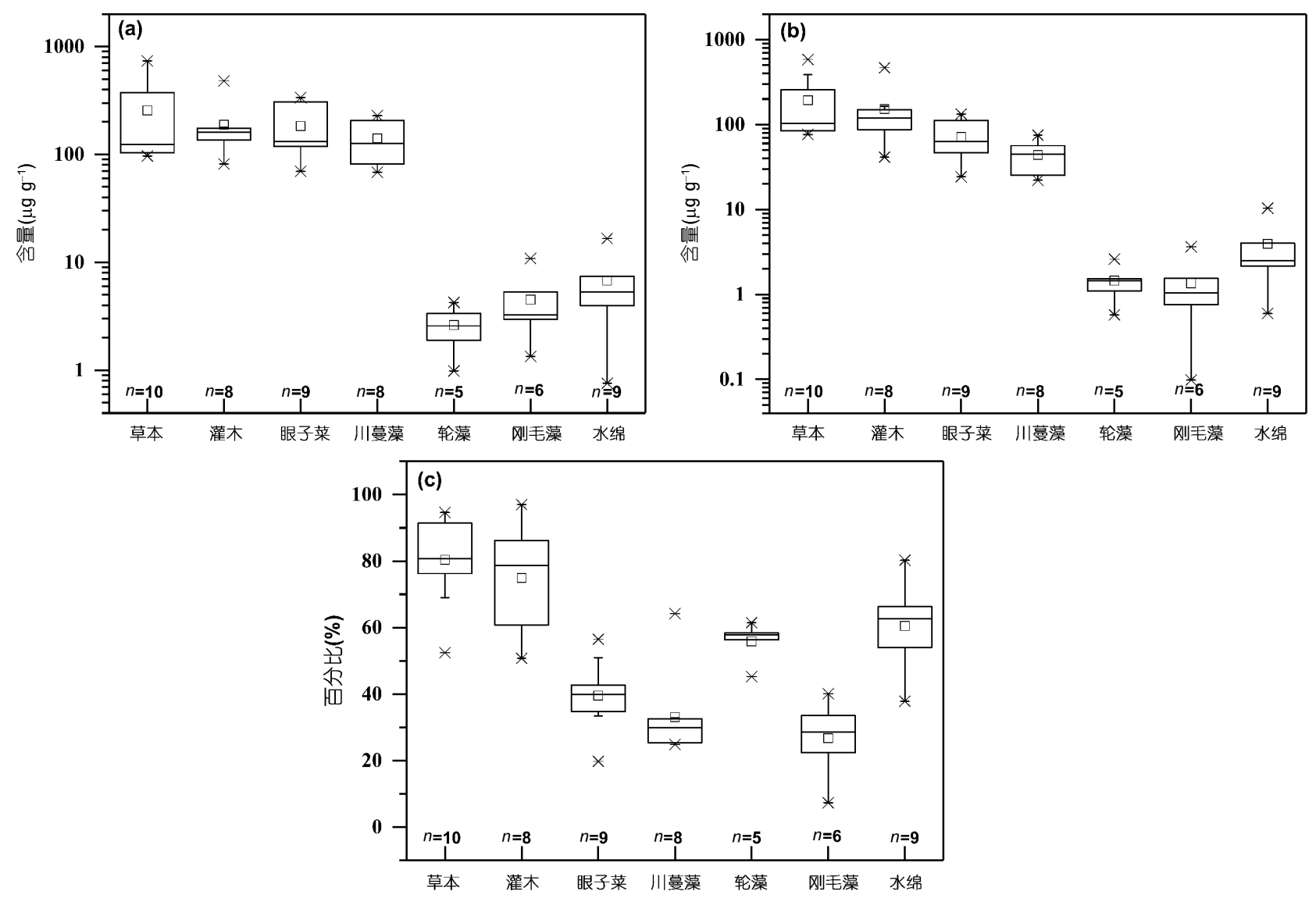

图 3 藻类、沉水植物和陆生植物的正构烷烃含量

(a) $\mathrm{C}_{21} \sim \mathrm{C}_{33}$ 含量; (b) $\mathrm{C}_{27} \sim \mathrm{C}_{33}$ 含量; (c) 长链正构烷烃与总正构䏓烃含量比值. 藻类: 轮藻、刚毛藻和水绵; 沉水植物: 眼子菜、狐尾藻和川蔓藻; 陆生植物: 草本、灌木

湖 2015 年6月湖水 $\delta \mathrm{D}$ 平均值为 $-38.0 \%$ ，9月份湖水 $\delta \mathrm{D}$ 平均值为 $-37.5 \%$ (表 1 ). 类似地, 托素湖 2015 年 6 月份 湖水 $\delta \mathrm{D}$ 平均值为 $14.0 \% \mathrm{o}, 2016$ 年 6 月份湖水 $\delta \mathrm{D}$ 平均值 为 $11.4 \%$ o(表 1$)$. 因此, 我们认为可以用雨季(2015年6月 和 9 月, 以及 2016 年 6 月)采集的湖水的 $\delta \mathrm{D}$ 值来计算这些 藻类和沉水植物的 $\varepsilon_{\mathrm{a} / \mathrm{w}}$ 值(表2). 同时, 为了计算陆生植 物相对于大气降水的 $\varepsilon_{\mathrm{a} / \mathrm{w}}$ 值, 我们根据Yao等(2013)和朱 建佳等(2015)的报道, 用德令哈市(距可鲁克湖 $40 \mathrm{~km}$, 距希里沟湖 $100 \mathrm{~km}) 6$ 月到 9 月大气降水的 $\delta \mathrm{D}$ 平均值 $(-40.7 \%)$ 进行计算.

由表2可知, 在藻类和沉水植物中, 眼子菜, 川蔓 藻, 轮藻, 刚毛藻和水绵的 $\varepsilon_{\mathrm{a} / \mathrm{w}}$ 值变化范围分别为 $-160 \sim$ $-149 \%$ 、-152 - 150\%。、-184 - 153\%、 - 154 $-149 \%$ 和 $-167 \sim-134 \%$, 平均值分别为 $-155 \%$ o $(n=7) 、-151 \% 0(n=3) 、-166 \% \mathrm{o}(n=4) 、-151 \% \mathrm{o}(n=3)$ 和
$-151 \% \mathrm{o}(n=2)$. 在陆生植物中, 草本和灌木 $\varepsilon_{\mathrm{a} / \mathrm{w}}$ 值变化范 围分别为 $-180 \sim-146 \%$ 和-140 - 73\% , 平均值分别为 $-164 \%$ o $(n=9)$ 和 $-109 \%$ o $(n=8)$.

\section{4 讨论}

\section{1＼cjkstart藻类和沉水植物对湖泊沉积物中正构烷烃的 影响}

青藏高原地区湖泊中藻类和沉水植物正构烷烃的 分布和含量表明其正构烷烃基本以 $\mathrm{C}_{23}$ 和 $\mathrm{C}_{25}$ 为主峰碳, 但它们通常也具有较高含量的 $\mathrm{C}_{27} \sim \mathrm{C}_{33}$ (图2和3). 沉水 植物 $\mathrm{C}_{27} \sim \mathrm{C}_{33}$ 的含量(眼子菜 $72 \mu \mathrm{g} \mathrm{g}^{-1}$ 、川蔓藻 $44 \mu \mathrm{g} \mathrm{g}^{-1}$ ) 略低于陆生植物(草本植物 $194 \mu \mathrm{g} \mathrm{g}^{-1}$ 、灌木 $153 \mu \mathrm{g} \mathrm{g}^{-1}$ ), 而藻类 $\mathrm{C}_{27} \sim \mathrm{C}_{33}$ 含量明显偏低(轮藻 $1.5 \mu \mathrm{g} \mathrm{g}^{-1}$ 、刚毛藻 $1.4 \mu \mathrm{g} \mathrm{g}^{-1}$ 、水绵 $\left.3.9 \mu \mathrm{g} \mathrm{g}^{-1}\right)($ 图3b). 因此, 这些新采集藻 
类和沉水植物正构烷烃含量与分布结果与我们此前的 结果基本一致(Liu和Liu, 2016), 进一步说明沉水植物 可能对湖泊沉积物中长链正构烷烃有较大贡献, 而藻 类的影响可能较小. 同时沉水植物通常在浅水区具有 较大生物量，表明其对浅水湖泊中正构烷烃的影响可 能更大(Aichner等, 2010a; Liu等, 2015).

\section{2 藻类和沉水植物正构烷烃 $\delta \mathrm{D}$ 值记录了湖水 $\delta \mathrm{D}$ 值的变化}

不同种属藻类和沉水植物正构烷烃 $\delta \mathrm{D}$ 值存在较 大变化, 尤其是眼子菜, 不同湖泊间 $\delta \mathrm{D}$ 值变化范围为 $-213 \sim-139 \%$, 差值达到 $74 \%$ o(网络版附表 4 ). 相关性分 析表明藻类和沉水植物 $\mathrm{C}_{29}$ 正构烷烃 $\delta \mathrm{D}$ 值与湖水 $\delta \mathrm{D}$ 值 存在明显相关性(藻类: $R^{2}=0.85, p<0.01, n=9$; 沉水植 物: $R^{2}=0.90, p<0.01, n=25$; 图4). 其中眼子菜作为青藏 高原湖泊中分布最广泛的沉水植物, 其 $\mathrm{C}_{29}$ 正构烷烃 $\delta \mathrm{D}$ 值与湖水 $\delta \mathrm{D}$ 值也存在明显相关性 $\left(R^{2}=0.92, p<0.01\right.$, $n=21$ )(图4c). Duan和Xu(2012)以及Duan等(2014)在青 海湖和甘南尔海的研究发现水生植物 $\delta \mathrm{D}$ 值受湖水蒸 发富集的影响．Liu等(2016)在青海湖的研究同样表明 水生植物 $\delta \mathrm{D}$ 值反映了湖水 $\delta \mathrm{D}$ 的变化. 其他研究也有类 似的结论(Sternberg, 1988; Guenther等, 2013). 因此, 我 们的结果基本与前人报道一致，同时表明在青藏高原 这种干旱半干旱区，藻类和沉水植物正构烷烃 $\delta \mathrm{D}$ 值很 好地记录了湖水 $\delta \mathrm{D}$ 值的变化.

\section{3 藻类和沉水植物 $\varepsilon_{\mathrm{a} / \mathrm{w}}$ 值的变化特征}

氢同位素分馏的研究对准确认识不同植物正构烷 烃 $\delta \mathrm{D}$ 值变化及应用 $\delta \mathrm{D}$ 值进行古水文重建至关重要, 但 目前对不同种属藻类和沉水植物氢同位素分馏的报道 十分有限. 由表 2 可知, 不同种属藻类和沉水植物样品 的 $\varepsilon_{\mathrm{a} / \mathrm{w}}$ 值不是稳定的, 这一现象在陆生植物中已有报道 (Gao等, 2014). 此外, 我们发现不同湖泊水文条件下生 长的同一种属植物的 $\varepsilon_{\mathrm{a} / \mathrm{w}}$ 值同样存在差别. 例如，苏干 湖和德令哈尔海的湖水 $\delta \mathrm{D}$ 值接近(苏干湖: $-0.5 \%$, $n=2$ 、尔海: $-2.1 \%, n=6)$ (表1), 但这两个湖中水绵样 品的 $\varepsilon_{\mathrm{a} / \mathrm{w}}$ 差值达到 $27 \% \mathrm{o}$ (表2). 苏干湖和尔海的水文条件 无明显差别, 但尔海的盐度高达 $90.6 \mathrm{~g} \mathrm{~L}^{-1}$ (Zhao等, 2008), 苏干湖的盐度为 $31.8 \mathrm{~g} \mathrm{~L}^{-1}$ (Qiang等，2005). 因 此, 我们认为盐度的差别可能是导致其水绵样品 $\varepsilon_{a / w}$ 值 存在差异的原因. 即随着湖泊盐度升高, 其中生长的藻
类的氢同位素分馏会减弱. 这一现象与前人研究结果 一致，即随着盐度升高，藻类会降低其细胞内的水与 湖水的交换速度，使藻类细胞内的水经反复利用后富 集 $\delta \mathrm{D}$ (Sachse等，2012；Maloney等，2016; Sachs等， 2016). 此外, 托素湖的盐度为 $38.7 \mathrm{~g} \mathrm{~L}^{-1}$ (Zhao Y 等, 2010), 与苏干湖的盐度接近, 这两个湖中生长的眼子 菜样品的 $\varepsilon_{\mathrm{a} / \mathrm{w}}$ 值也接近(表2). 因此, 虽然样品量有限, 但 我们在这些天然湖泊中观察到的盐度与正构烷烃 $\varepsilon_{\mathrm{a} / \mathrm{w}}$ 值的关系很好的补充了前人培养实验所得结果(例如, Schouten等, 2006; M’boule等, 2014; Maloney等, 2016; Sachs等, 2016). 湖水的盐度可能受多种环境条件的影 响, 但湖水的蒸发富集强度在咸水湖会尤其明显 (Aichner等, 2010b; Liu等, 2017). 结合图4和表2的结 果, 我们认为湖水 $\delta \mathrm{D}$ 值可能是湖泊中藻类和沉水植物 正构烷烃 $\delta \mathrm{D}$ 值的主要控制因素, 但环境条件, 尤其是 盐度的改变, 可能会影响这些植物的 $\delta \mathrm{D}$ 值. 因此, 湖泊 沉积物中来源于藻类和沉水植物的正构烷烃可能是重 建古湖水 $\delta \mathrm{D}$ 值及湖泊古盐度的重要指标.

\section{4 藻类、沉水植物和陆生植物正构烷烃 $\delta \mathrm{D}$ 值的 比较}

前人研究结果表明陆生木本植物正构烷烃 $\delta \mathrm{D}$ 值 一般比草本植物 $\delta \mathrm{D}$ 值偏正(例如, Liu等, 2006; Hou等, 2007; Liu和Yang, 2008; Yang等, 2011; Duan和Xu, 2012; Duan等, 2014). 但在不同类型湖泊中(开放湖和 封闭湖), 目前尚没有研究分析藻类和沉水植物是否能 记录了湖水相对大气降水富集 $\delta \mathrm{D}$ 值的信号. 由于青藏 高原东北部地区草本植物与湖泊中藻类和沉水植物相 对于它们源水的 $\varepsilon_{\mathrm{a} / \mathrm{w}}$ 值接近(草本: $-164 \%$, 藻类和沉水 植物: $-155 \%$ )(表 2$)$, 而木本植物 $\varepsilon_{\mathrm{a} / \mathrm{w}}$ 值明显偏正 $(-109 \%$; 表 2$)$. 因此我们将湖边草本植物与湖泊中藻 类和沉水植物的 $\delta \mathrm{D}$ 值进行了比较(图5).

德令哈市夏季大气降水的 $\delta \mathrm{D}$ 平均值为 $-40.7 \%$ 。 (Yao等, 2013; 朱建佳等, 2015), 而由于湖水蒸发作用 较强, 希里沟湖的湖水 $\delta \mathrm{D}$ 平均值为 $-11.5 \%$ (表 1$)$. 将希 里沟湖(封闭湖)中生长的川蔓藻 $\delta \mathrm{D}$ 和湖边草本植物的 $\delta \mathrm{D}$ 值进行比较, 我们发现这些川蔓藻的 $\delta \mathrm{D}$ 值(平均值 $-154 \%, n=11$ ) 明显偏正于草本植物的 $\delta \mathrm{D}$ 值 (平均值 $-201 \%$, $n=4$; one-way ANOVA, $p<0.01$ )(图5). 不同水 源的 $\delta \mathrm{D}$ 值基本记录了大气降水的 $\delta \mathrm{D}$ 变化, 但受到其他 多种环境条件的影响, 其中蒸发富集是影响湖水 $\delta \mathrm{D}$ 值 

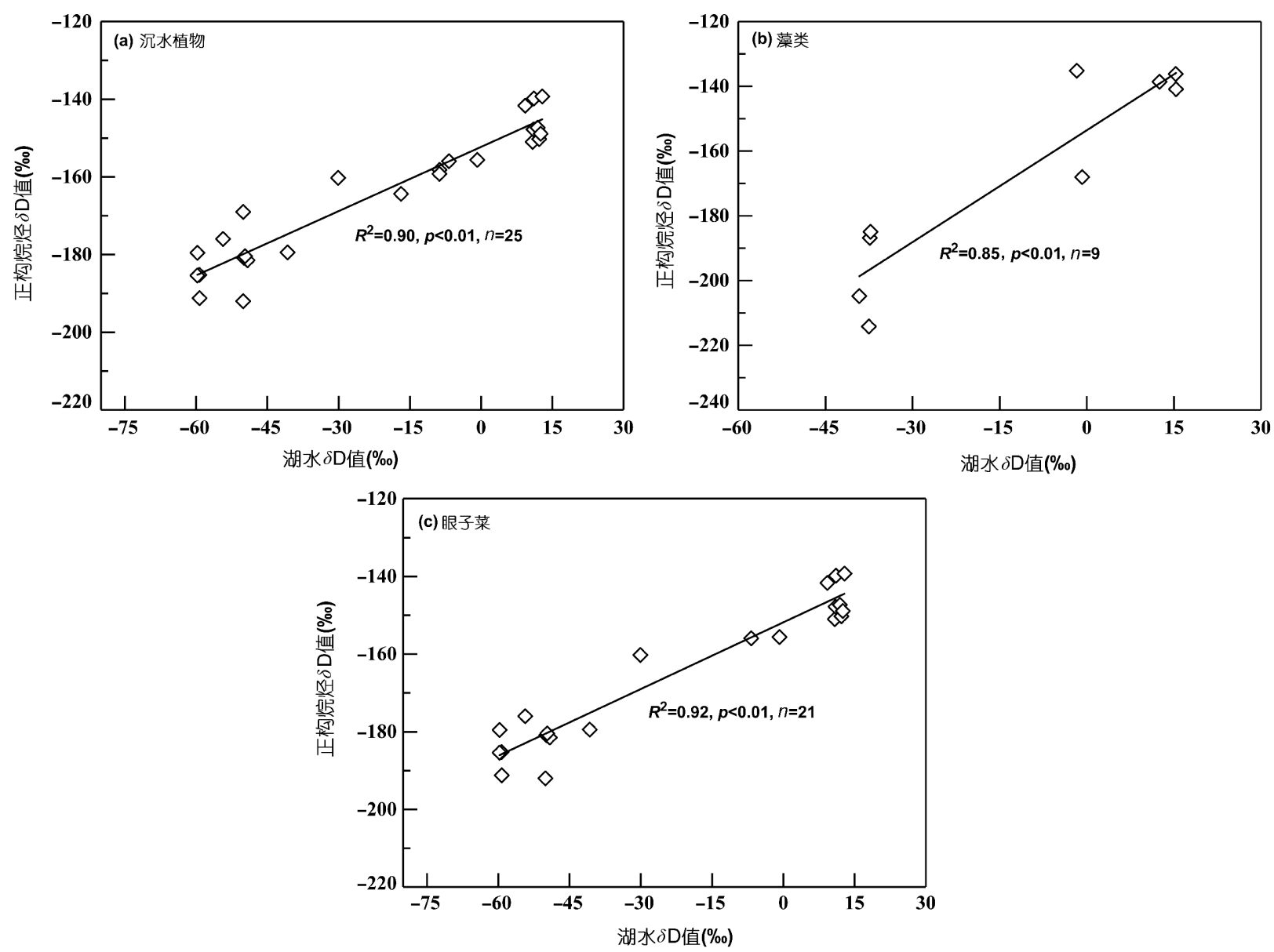

图 4 藻类和沉水植物 $\mathrm{C}_{29}$ 正构烷烃 $\delta \mathrm{D}$ 值记与湖水 $\delta \mathrm{D}$ 值的相关性分析

(a) 沉水植物; (b) 藻类; (c) 眼子菜

的重要因素. 因此, 我们的结果表明生长于封闭湖泊中 的沉水植物能够记录湖水相对大气降水富集 $\delta \mathrm{D}$ 值的 信号. 其他封闭湖如青海湖和纳木错报道的水生和草 本植物正构烷烃 $\delta \mathrm{D}$ 值也有类似的现象 (Mügler 等, 2008; Duan和Xu, 2012; Liu等, 2016).

但在开放湖, 如可鲁克湖, 这种关系并不一致. 可 鲁克湖的湖水主要由巴音河和巴勒根河供给, 其湖水 通过连湖河流向托素湖. 其湖水 $\delta \mathrm{D}$ 平均值为 $-38 \%$ (表 $1)$, 与此地夏季大气降水 $\delta \mathrm{D}$ 值 $(-40.7 \%$; Yao等, 2013 ; 朱建佳等, 2015)接近, 表明蒸发作用对可鲁克湖的湖 水 $\delta \mathrm{D}$ 值影响较小. 此湖中轮藻样品 $\delta \mathrm{D}$ 平均值 $(-198 \%$, $n=4)$ 与其湖边草本植物 $\delta \mathrm{D}$ 平均值 $(-196 \%, n=4)$ 差别很 小(图5), 表明开放湖中生长的藻类与其湖边草本植物 $\delta \mathrm{D}$ 值无明显差别 (one-way ANOVA, $p=0.826>0.05$ ).

综上所述, 我们的结果表明在干旱半干旱地区, 仅
封闭湖中生长的藻类或沉水植物记录了湖水相对大气 降水富集 $\delta \mathrm{D}$ 值的信号.

\section{5 古环境应用}

在利用湖泊沉积物中正构烷烃氢同位素组成进行 古环境重建时, 常用不同碳数正构烷烃 $\delta \mathrm{D}$ 值的差值来 进行分析(Mügler等, 2008; Aichner等, 2010b; Guenther 等, 2013; Rao等, 2014; Wang等, 2016; Liu等, 2017). 例 如Aichner等(2010b)报道了寇察湖16ka以来正构烷烃 $\delta \mathrm{D}$ 记录, 用 $\Delta \delta \mathrm{D}_{\text {mid-n-C31 }}$ 值反映湿润或干旱的气候条件. $\mathrm{Liu}$ 等(2017)报道了青海湖 $12 \mathrm{ka}$ 以来正构烷烃 $\delta \mathrm{D}$ 值变 化, 用 $\mathrm{C}_{31}$ 和 $\mathrm{C}_{29}$ 的 $\delta \mathrm{D}$ 差值来反映历史时期湖泊的蒸发 状态. 此方法的一个基本前提是认为来源于藻类和沉 水植物的不同碳数正构烷烃的 $\delta \mathrm{D}$ 值无明显差别. 而目 前少有报道对每个藻类和沉水植物样品不同碳数正构 


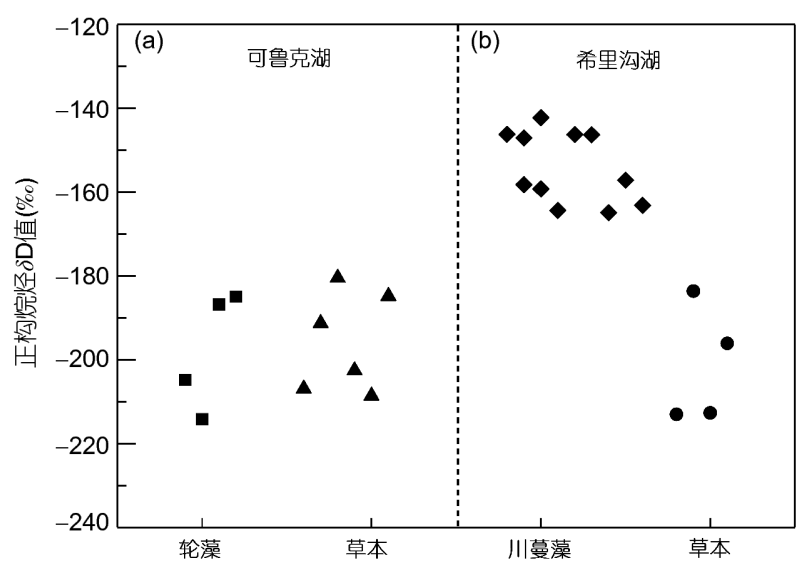

图 5 正构烷烃 $\delta \mathrm{D}$ 值的比较

(a) 可鲁克湖 (开放湖)中轮藻和湖边草本植物 $\delta \mathrm{D}$ 值比较; (b) 希里沟 湖(封闭湖)中川蔓藻和湖边草本植物 $\delta \mathrm{D}$ 值比较

烷烃的 $\delta \mathrm{D}$ 值进行比较, 仅Liu等(2016)在青海湖的研究 发现, 同一个藻类和沉水植物样品 $\mathrm{C}_{27} 、 \mathrm{C}_{29}$ 和 $\mathrm{C}_{31}$ 正构 烷烃 $\delta \mathrm{D}$ 值无明显差别.

在本研究中, 我们采集了青藏高原东北部地区 15 各湖泊中不同种属的藻类和沉水植物样品, 测定了它 们 $\mathrm{C}_{21} \sim \mathrm{C}_{31}$ 奇碳数正构烷烃 $\delta \mathrm{D}$ 值, 希望对Liu等(2016)在 青海湖的研究结果进行补充. 结果表明: 每一个沉水植 物(包括眼子菜、狐尾藻和川蔓藻; 图6a和网络版附表 4)和藻类样品(包括轮藻、刚毛藻和水绵; 图6c和网络 版附表4)的不同奇碳数正构烷烃 $\delta \mathrm{D}$ 值无明显差别，大 部分样品 $\delta \mathrm{D}$ 差值落在 $\pm 5 \%$ 范围内 (图6b 和 $\mathrm{d}$ ), 与实验测 定误差接近. 此外, 我们对Aichner等(2010b)和Mügler 等(2008)报道的水生植物 $\delta \mathrm{D}$ 值进行分析，发现其不同 碳数正构烷烃 $\delta \mathrm{D}$ 差值基本小于 $\pm 6 \%$ (图6e). 因此, 我们 认为藻类和沉水植物不同碳数正构烷烃 $\delta \mathrm{D}$ 值间的差 异很小, 而陆生植物 $\delta \mathrm{D}$ 值的研究中发现了类似的现象 (例如，Liu等，2006; Smith和Freeman，2006; Hou等， 2007; Liu和Yang, 2008; Mügler等, 2008; Feakins和 Sessions, 2010; Yang等, 2011; Daniels等, 2017; Zhang 等, 2017). 这一结论对于应用湖泊沉积物正构烷烃 $\delta \mathrm{D}$ 值进行古环境重建有重要意义.

由于同一植物来源的不同碳数正构烷烃的 $\delta \mathrm{D}$ 值 无明显差别, 因此, 在利用湖泊沉积物进行古气候研究 中, 可以根据其不同碳数正构烷烃 $\delta \mathrm{D}$ 值的差值大小帮 助我们判断历史时期湖泊沉积物中正构烷烃的植物来 源. 例如, 如果湖泊沉积物 $\mathrm{C}_{23} 、 \mathrm{C}_{25}$ 与 $\mathrm{C}_{27} 、 \mathrm{C}_{29} 、 \mathrm{C}_{31}$ 的 $\delta \mathrm{D}$ 值存在较大差别, 但 $\mathrm{C}_{27} 、 \mathrm{C}_{29} 、 \mathrm{C}_{31}$ 的 $\delta \mathrm{D}$ 值无明显差 别, 说明湖泊沉积物中长链 $\left(\mathrm{C}_{27} \sim \mathrm{C}_{31}\right)$ 正构烷烃主要来 自陆生植物. 如果 $\mathrm{C}_{31}$ 与其他碳数正构烷烃 $\delta \mathrm{D}$ 值相差较 大, 但 $\mathrm{C}_{23} 、 \mathrm{C}_{25}$ 与 $\mathrm{C}_{27}, \mathrm{C}_{29}$ 正构烷烃 $\delta \mathrm{D}$ 值无明显差别, 可 能意味着湖泊中 $\mathrm{C}_{27}$ 和 $\mathrm{C}_{29}$ 正构烷烃受沉水植物的影响 较大. 如果湖泊沉积物中不同碳数正构烷烃 $\delta \mathrm{D}$ 值均无 明显差别, 可能说明其来源于单一植物来源. 当然这种 方法可能更适用于封闭湖, 因为仅封闭湖中生长的藻 类或沉水植物记录了湖水相对大气降水富集 $\delta \mathrm{D}$ 值的 信号. 此外, 我们必须强调陆生植被类型的变化可能也 会导致不同链长正构烷烃 $\delta \mathrm{D}$ 差值发生变化，但其他指 标, 如Paq、ACL或正构烷烃单体 $\delta^{13} \mathrm{C}$ 值等能帮助我们 区分沉积物中正构烷烃的植物来源. 如Liu等(2015)发 现不同碳数正构烷烃 $\delta^{13} \mathrm{C}$ 值的差值 $\left(\mathrm{C}_{27} 、 \mathrm{C}_{29}\right.$ 和 $\left.\mathrm{C}_{31}\right)$ 能 够判别湖泊沉积物中水生植物的贡献, 因为沉水植物 的 ${ }^{13} \mathrm{C}$ 值一般偏正于陆生 $\mathrm{C}_{3}$ 植物. 因此, 在利用湖泊沉 积物正构烷烃进行古环境重建时, 将其 $\delta \mathrm{D}$ 和 $\delta^{13} \mathrm{C}$ 值结 合起来分析能够更准确判断沉积物中正构烷烃的植物 来源.

此外, 湖泊沉积物中 $\mathrm{C}_{23}$ 和 $\mathrm{C}_{25}$ 认为主要来自于水生 植物(Ficken等, 2000; Gao等, 2011), $\mathrm{C}_{31}$ 认为主要来自 陆生植物(Liu等, 2015, 2016). 而在干旱半干旱地区, 仅 封闭湖中生长的藻类或沉水植物记录了湖水相对大气 降水富集 $\delta \mathrm{D}$ 值的信号(图5). 因此, 我们认为分析湖泊 沉积物中不同碳数正构烷烃 $\delta \mathrm{D}$ 值是否存在差别能够 帮助判别历史时期湖泊盆地的沉积是属于开放湖盆沉 积, 还是封闭湖盆沉积. 例如, 如果湖泊沉积物 $\mathrm{C}_{23}$ 和 $\mathrm{C}_{25}$ 正构烷烃的 $\delta \mathrm{D}$ 值明显偏正于 $\mathrm{C}_{31}$ 的 $\delta \mathrm{D}$ 值, 表明该时期 湖泊湖水蒸发富集作用较强, 属于封闭湖泊沉积. 相 反, 如果 $\mathrm{C}_{23}$ 和 $\mathrm{C}_{25}$ 正构烷烃的 $\delta \mathrm{D}$ 值与 $\mathrm{C}_{31}$ 的 $\delta \mathrm{D}$ 值无明显 差别, 指示该时期湖泊属于开放沉积类型. 当然, 结合 沉积学或古生物学指标应用这种方法时, 干旱半干旱 地区的湖泊可能更加适用, 因为该区域的湖泊湖水蒸 发富集作用最明显.

\section{5 结论}

通过系统调查青藏高原地区 15 个湖泊中的 51 个沉 水植物、13 个藻类和 20 个湖边陆生植物正构烷烃的 $\delta \mathrm{D}$ 值, 我们发现藻类和沉水植物正构烷烃 $\delta \mathrm{D}$ 值与湖水 $\delta \mathrm{D}$ 值显著正相关. 但不同水文条件下的同一种属植物 

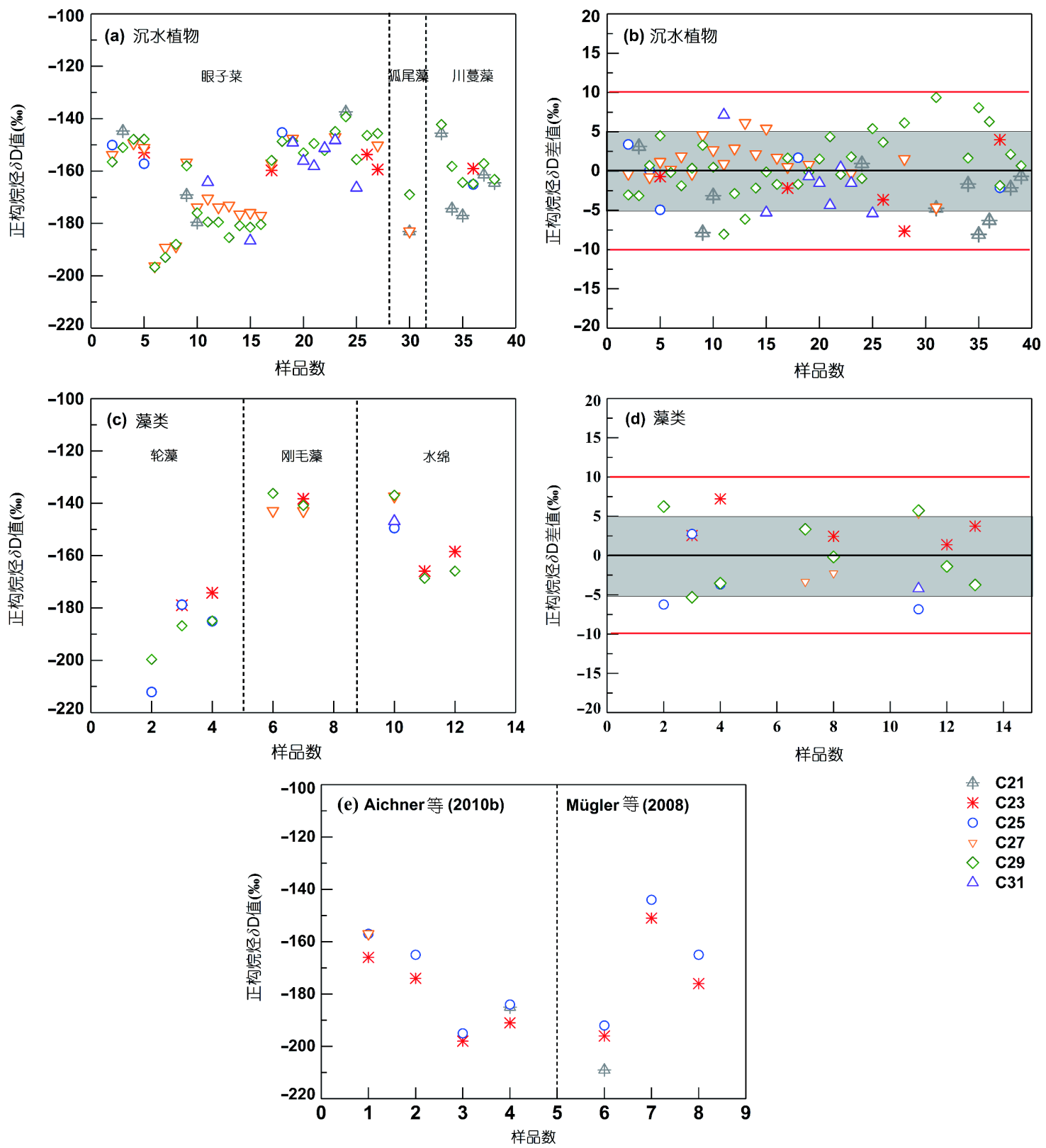

4 $\mathrm{C} 21$

* $\mathrm{C} 23$

○ $\mathbf{C 2 5}$

$\diamond \begin{array}{ll}\mathbf{C} 27 \\ \diamond \mathbf{C 2 9}\end{array}$

$\triangle \mathrm{C} 31$

图 6 不同碳数正构烷烃 $\delta \mathrm{D}$ 值的比较

不同的颜色和形状表示不同链长正构烷烃. (a) 沉水植物(包括眼子菜、狐尾藻和川蔓藻)每个样品的 $\delta \mathrm{D}$ 值; (b) 沉水植物不同碳数正构烷烃 $\delta \mathrm{D}$ 的差值(灰线表示 $\pm 5 \%$ 偏差, 红线表示 $\pm 10 \%$ 偏差); (c) 藻类(包括轮藻、刚毛藻和水绵)每个样品的 $\delta \mathrm{D}$ 值; (d) 藻类不同碳数正构烷烃 $\delta \mathrm{D}$ 的差值 (灰线表示 $\pm 5 \%$ 偏差, 红线表示 $\pm 10 \%$ 偏差); (e) Aichner等(2010b)和Mügler等(2008)报道的水生植物 $\delta \mathrm{D}$ 值

的 $\varepsilon_{a / w}$ 值并不稳定，表明除了湖水 $\delta \mathrm{D}$ 值，其他环境条件 (如盐度)也会影响藻类和沉水植物的 $\delta \mathrm{D}$ 值. 此外, 希里 沟湖(封闭湖)中川蔓藻的 $\delta \mathrm{D}$ 值显著偏正于其湖边草本 植物，但可鲁克湖(开放湖)中轮藻植物与其湖边草本 植物的 $\delta \mathrm{D}$ 值接近，表明干旱半干旱地区湖泊中藻类和
沉水植物仅在封闭湖记录了湖水相对于大气降水富集 $\delta \mathrm{D}$ 值的信号. 对每一个藻类和沉水植物样品, $\mathrm{C}_{21}$ 、 $\mathrm{C}_{23} 、 \mathrm{C}_{25} 、 \mathrm{C}_{27} 、 \mathrm{C}_{29}$ 和 $\mathrm{C}_{31}$ 正构烷烃的 $\delta \mathrm{D}$ 值无明显差别, 表明不同碳数正构烷烃对源水 $\delta \mathrm{D}$ 值的响应是一致的. 本研究进一步认识了不同碳数正构烷烃分子间的差 
异，表明不同链长正构烷烃 $\delta \mathrm{D}$ 值的差值能帮助我们判 断湖泊沉积物中正构烷烃的植物来源，及判断古湖泊 盆地的沉积类型.

致谢感谢李祥忠博士在野外采样过程中给予的帮助, 感谢王政和王欢业博士在气相色谱分析和单体氢同位素 测试中给予的帮助, 感谢审稿人提出的有益建议.

\section{参考文献}

朱建佳, 陈辉, 巩国丽. 2015. 柴达木盆地东部降水氢氧同位素特征 与水汽来源. 环境科学, 8: 2784-2790

Aichner B, Herzschuh U, Wilkes H. 2010a. Influence of aquatic macrophytes on the stable carbon isotopic signatures of sedimentary organic matter in lakes on the Tibetan Plateau. Org Geochem, 41: 706-718

Aichner B, Herzschuh U, Wilkes H, Schulz H M, Wang Y, Plessen B, Mischke S, Diekmann B, Zhang C. 2012. Ecological development of Lake Donggi Cona, north-eastern Tibetan Plateau, since the late glacial on basis of organic geochemical proxies and non-pollen palynomorphs. Palaeogeogr Palaeoclimatol Palaeoecol, 313-314: 140-149

Aichner B, Herzschuh U, Wilkes H, Vieth A, Böhner J. 2010b. $\delta$ D values of $n$-alkanes in Tibetan lake sediments and aquatic macrophytes-A surface sediment study and application to a 16 ka record from Lake Koucha. Org Geochem, 41: 779-790

An Z, Porter S C, Kutzbach J E, Wu X, Wang S, Liu X, Zhou W. 2000. Asynchronous holocene optimum of the East Asian monsoon. Quat Sci Rev, 19: 743-762

An Z, Kutzbach J E, Prell W L, Porter S C. 2001. Evolution of Asian monsoons and phased uplift of the Himalaya-Tibetan plateau since Late Miocene times. Nature, 411: 62-66

Cao Y, Liu W, Sauer P E, Wang Z, Li Z. 2012. An evaluation of alumina reaction tube conditioning for high-precision ${ }^{2} \mathrm{H} /{ }^{1} \mathrm{H}$ isotope measurements via gas chromatography/thermal conversion/isotope ratio mass spectrometry. Rapid Commun Mass Spectrom, 26: 2577 2583

Cranwell P A, Eglinton G, Robinson N. 1987. Lipids of aquatic organisms as potential contributors to lacustrine sediments--II. Org Geochem, 11: 513-527

Currie B S, Rowley D B, Tabor N J. 2005. Middle Miocene paleoaltimetry of southern Tibet: Implications for the role of mantle thickening and delamination in the Himalayan orogen. Geology, 33: 181

Daniels W C, Russell J M, Giblin A E, Welker J M, Klein E S, Huang Y. 2017. Hydrogen isotope fractionation in leaf waxes in the
Alaskan Arctic tundra. Geochim Cosmochim Acta, 213: 216-236

DeCelles P G, Quade J, Kapp P, Fan M, Dettman D L, Ding L. 2007. High and dry in central Tibet during the Late Oligocene. Earth Planet Sci Lett, 253: 389-401

Dietze E, Wünnemann B, Hartmann K, Diekmann B, Jin H, Stauch G, Yang S, Lehmkuhl F. 2013. Early to mid-Holocene lake high-stand sediments at Lake Donggi Cona, northeastern Tibetan Plateau, China. Quat Res, 79: 325-336

Duan Y, Wu Y, Cao X, Zhao Y, Ma L. 2014. Hydrogen isotope ratios of individual $n$-alkanes in plants from Gannan Gahai Lake (China) and surrounding area. Org Geochem, 77: 96-105

Duan Y, Xu L. 2012. Distributions of n-alkanes and their hydrogen isotopic composition in plants from Lake Qinghai (China) and the surrounding area. Appl Geochem, 27: 806-814

Eglinton T I, Eglinton G. 2008. Molecular proxies for paleoclimatology. Earth Planet Sci Lett, 275: 1-16

Feakins S J, Sessions A L. 2010. Controls on the D/H ratios of plant leaf waxes in an arid ecosystem. Geochim Cosmochim Acta, 74: 21282141

Feakins S J, Bentley L P, Salinas N, Shenkin A, Blonder B, Goldsmith G R, Ponton C, Arvin L J, Wu M S, Peters T, West A J, Martin R E, Enquist B J, Asner G P, Malhi Y. 2016. Plant leaf wax biomarkers capture gradients in hydrogen isotopes of precipitation from the Andes and Amazon. Geochim Cosmochim Acta, 182: 155-172

Ficken K J, Li B, Swain D L, Eglinton G. 2000. An $n$-alkane proxy for the sedimentary input of submerged/floating freshwater aquatic macrophytes. Org Geochem, 31: 745-749

Gao L, Hou J, Toney J, MacDonald D, Huang Y. 2011. Mathematical modeling of the aquatic macrophyte inputs of mid-chain n-alkyl lipids to lake sediments: Implications for interpreting compound specific hydrogen isotopic records. Geochim Cosmochim Acta, 75: 3781-3791

Gao L, Edwards E J, Zeng Y, Huang Y. 2014. Major evolutionary trends in hydrogen isotope fractionation of vascular plant leaf waxes. Plos One, 9: e112610

Guenther F, Aichner B, Siegwolf R, Xu B, Yao T, Gleixner G. 2013. A synthesis of hydrogen isotope variability and its hydrological significance at the Qinghai-Tibetan Plateau. Quat Int, 313-314: 3-16

He Y, Zhao C, Wang Z, Wang H, Song M, Liu W, Liu Z. 2013. Late Holocene coupled moisture and temperature changes on the northern Tibetan Plateau. Quat Sci Rev, 80: 47-57

Henderson A C G, Holmes J A. 2009. Palaeolimnological evidence for environmental change over the past millennium from Lake Qinghai sediments: A review and future research prospective. Quat Int, 194: 134-147

Henderson A C G, Holmes J A, Leng M J. 2010. Late Holocene isotope 
hydrology of Lake Qinghai, NE Tibetan Plateau: Effective moisture variability and atmospheric circulation changes. Quat Sci Rev, 29: 2215-2223

Herzschuh U, Winter K, Wunnemann B, Li S. 2006. A general cooling trend on the central Tibetan Plateau throughout the Holocene recorded by the Lake Zigetang pollen spectra. Quat Int, 154-155: $113-121$

Hou J, D'Andrea W J, MacDonald D, Huang Y. 2007. Hydrogen isotopic variability in leaf waxes among terrestrial and aquatic plants around Blood Pond, Massachusetts (USA). Org Geochem, 38: 977-984

Li X, Liu W. 2017. Lake evolution and hydroclimate variation at Lake Qinghai (China) over the past $32 \mathrm{ka}$ inferred from ostracods and their stable isotope composition. J Paleolimnol, 58: 299-316

Lister G S, Kelts K, Zao C K, Yu J Q, Niessen F. 1991. Lake Qinghai, China: Closed-basin like levels and the oxygen isotope record for ostracoda since the latest Pleistocene. Palaeogeogr Palaeoclimatol Palaeoecol, 84: 141-162

Liu H, Liu W. 2016. $n$-alkane distributions and concentrations in algae, submerged plants and terrestrial plants from the Qinghai-Tibetan Plateau. Org Geochem, 99: 10-22

Liu W, Liu H, Wang Z, An Z, Cao Y. 2017. Hydrogen isotopic compositions of long-chain leaf wax $n$-alkanes in Lake Qinghai sediments record palaeohydrological variations during the past 12 ka. Quat Int, 449: 67-74

Liu W, Wang Z, Cui L, Sauer P E, Cao Y. 2012. Variation of compound-specific hydrogen isotope ratios under changing temperature program in gas chromatography/thermal conversion/isotope ratio mass spectrometry. Rapid Commun Mass Spectrom, 26: 17461752

Liu W, Yang H. 2008. Multiple controls for the variability of hydrogen isotopic compositions in higher plant $n$-alkanes from modern ecosystems. Glob Change Biol, 14: 2166-2177

Liu W, Yang H, Li L. 2006. Hydrogen isotopic compositions of $n$ alkanes from terrestrial plants correlate with their ecological life forms. Oecologia, 150: 330-338

Liu W, Yang H, Wang H, An Z, Wang Z, Leng Q. 2015. Carbon isotope composition of long chain leaf wax $n$-alkanes in lake sediments: A dual indicator of paleoenvironment in the Qinghai-Tibet Plateau. Org Geochem, 83-84: 190-201

Liu W G, Yang H, Wang H Y, Yao Y, Wang Z, Cao Y N. 2016. Influence of aquatic plants on the hydrogen isotope composition of sedimentary long-chain $n$-alkanes in the Lake Qinghai region, Qinghai-Tibet Plateau. Sci China Earth Sci, 59: 1368-1377

M'boule D, Chivall D, Sinke-Schoen D, Sinninghe Damsté J S, Schouten S, van der Meer M T J. 2014. Salinity dependent hydrogen isotope fractionation in alkenones produced by coastal and open ocean haptophyte algae. Geochim Cosmochim Acta, 130: 126-135 Mischke S, Aichner B, Diekmann B, Herzschuh U, Plessen B, Wünnemann B, Zhang C. 2010. Ostracods and stable isotopes of a late glacial and Holocene lake record from the NE Tibetan Plateau. Chem Geol, 276: 95-103

Mügler I, Sachse D, Werner M, Xu B, Wu G, Yao T, Gleixner G. 2008. Effect of lake evaporation on $\delta \mathrm{D}$ values of lacustrine $n$-alkanes: A comparison of Nam Co (Tibetan Plateau) and Holzmaar (Germany). Org Geochem, 39: 711-729

Maloney A E, Shinneman A L C, Hemeon K, Sachs J P. 2016. Exploring lipid ${ }^{2} \mathrm{H} /{ }^{1} \mathrm{H}$ fractionation mechanisms in response to salinity with continuous cultures of the diatom Thalassiosira pseudonana. Org Geochem, 101: 154-165

Opitz S, Wünnemann B, Aichner B, Dietze E, Hartmann K, Herzschuh U, IJmker J, Lehmkuhl F, Li S, Mischke S, Plotzki A, Stauch G, Diekmann B. 2012. Late Glacial and Holocene development of Lake Donggi Cona, north-eastern Tibetan Plateau, inferred from sedimentological analysis. Palaeogeogr Palaeoclimatol Palaeoecol, 337338: $159-176$

Polissar P J, Freeman K H, Rowley D B, McInerney F A, Currie B S. 2009. Paleoaltimetry of the Tibetan Plateau from $\mathrm{D} / \mathrm{H}$ ratios of lipid biomarkers. Earth Planet Sci Lett, 287: 64-76

Qiang M, Chen F, Zhang J, Gao S, Zhou A. 2005. Climatic changes documented by stable isotopes of sedimentary carbonate in Lake Sugan, northeastern Tibetan Plateau of China, since 2 ka BP. Chin Sci Bull, 50: 1930-1939

Qiang M, Liu Y, Jin Y, Song L, Huang X, Chen F. 2014. Holocene record of eolian activity from Genggahai Lake, northeastern Qinghai-Tibetan Plateau, China. Geophys Res Lett, 41: 589-595

Qiang M, Song L, Chen F, Li M, Liu X, Wang Q. 2013. A 16-ka lakelevel record inferred from macrofossils in a sediment core from Genggahai Lake, northeastern Qinghai-Tibetan Plateau (China). J Paleolimnol, 49: 575-590

Rao Z, Jia G, Qiang M, Zhao Y. 2014. Assessment of the difference between mid- and long chain compound specific $\delta \mathrm{D} n$-alkanes values in lacustrine sediments as a paleoclimatic indicator. Org Geochem, 76: 104-117

Rao Z, Zhu Z, Jia G, Henderson A C G, Xue Q, Wang S. 2009. Compound specific $\delta \mathrm{D}$ values of long chain $n$-alkanes derived from terrestrial higher plants are indicative of the $\delta \mathrm{D}$ of meteoric waters: Evidence from surface soils in eastern China. Org Geochem, 40: 922-930

Sachs J P, Maloney A E, Gregersen J, Paschall C. 2016. Effect of salinity on ${ }^{2} \mathrm{H} /{ }^{1} \mathrm{H}$ fractionation in lipids from continuous cultures of the coccolithophorid Emiliania huxleyi. Geochim Cosmochim Acta, 
189: 96-109

Sachse D, Billault I, Bowen G J, Chikaraishi Y, Dawson T E, Feakins S J, Freeman K H, Magill C R, McInerney F A, van der Meer M T J, Polissar P, Robins R J, Sachs J P, Schmidt H L, Sessions A L, White J W C, West J B, Kahmen A. 2012. Molecular paleohydrology: Interpreting the hydrogen-isotopic composition of lipid biomarkers from photosynthesizing organisms. Annu Rev Earth Planet Sci, 40: 221-249

Sachse D, Radke J, Gleixner G. 2006. $\delta$ D values of individual $n$-alkanes from terrestrial plants along a climatic gradient-Implications for the sedimentary biomarker record. Org Geochem, 37: 469-483

Schouten S, Ossebaar J, Schreiber K, Kienhuis M V M, Langer G, Benthien A, Bijma J. 2006. The effect of temperature, salinity and growth rate on the stable hydrogen isotopic composition of long chain alkenones produced by Emiliania huxleyi and Gephyrocapsa oceanica. Biogeosciences, 3: 113-119

Sessions A L, Sylva S P, Summons R E, Hayes J M. 2004. Isotopic exchange of carbon-bound hydrogen over geologic timescales. Geochim Cosmochim Acta, 68: 1545-1559

Smith F A, Freeman K H. 2006. Influence of physiology and climate on $\delta \mathrm{D}$ of leaf wax $n$-alkanes from $\mathrm{C}_{3}$ and $\mathrm{C}_{4}$ grasses. Geochim Cosmochim Acta, 70: 1172-1187

Sternberg L. 1988. D/H ratios of environmental water recorded by $\mathrm{D} / \mathrm{H}$ ratios of plant lipids. Nature, 333: 59-61

Tuo J, Wu C, Zhang M, Chen R. 2011. Distribution and carbon isotope composition of lipid biomarkers in Lake Erhai and Lake Gahai sediments on the Tibetan Plateau. J Great Lakes Res, 37: 447-455

Wang Y, Zhu L, Wang J, Ju J, Peng P, Lin X, Hu J, Nishimura M. 2016. Paleohydrological processes revealed by $n$-alkane $\delta \mathrm{D}$ in lacustrine sediments of Lake Pumoyum Co, southern Tibetan Plateau, and their response to climate changes during the past 18.5 cal ka. J Paleolimnol, 56: 223-238

Wang Z, Liu W, Liu Z, Wang H, He Y, Zhang F. 2013. A 1700-year nalkanes hydrogen isotope record of moisture changes in sediments from Lake Sugan in the Qaidam Basin, northeastern Tibetan Plateau. Holocene, 23: 1350-1354

Wischnewski J, Mischke S, Wang Y, Herzschuh U. 2011. Reconstructing climate variability on the northeastern Tibetan Plateau since the last Lateglacial-A multi-proxy, dual-site approach comparing terrestrial and aquatic signals. Quat Sci Rev, 30: 82-97

Xie Y, Xu B Q, Wu G J, Lin S B. 2012. Influence of variation in precipitation on the $\delta \mathrm{D}$ values of terrestrial $n$-alkanes on the southern Tibetan Plateau. Chin Sci Bull, 57: 2140-2147

Yang H, Liu W, Leng Q, Hren M T, Pagani M. 2011. Variation in $n$ alkane $\delta \mathrm{D}$ values from terrestrial plants at high latitude: Implications for paleoclimate reconstruction. Org Geochem, 42: 283-288

Yao T, Masson-Delmotte V, Gao J, Yu W, Yang X, Risi C, Sturm C, Werner M, Zhao H, He Y, Ren W, Tian L, Shi C, Hou S. 2013. A review of climatic controls on $\delta^{18} \mathrm{O}$ in precipitation over the Tibetan Plateau: Observations and simulations. Rev Geophys, 51: 525-548

Yu G, Tang L, Yang X, Ke X, Harrison S P. 2001. Modern pollen samples from alpine vegetation on the Tibetan Plateau. Glob Ecol Biogeogr, 10: 503-519

Zhang X, Xu B, Günther F, Mügler I, Lange M, Zhao H, Li J, Gleixner G. 2017. Hydrogen isotope ratios of terrestrial leaf wax $n$-alkanes from the Tibetan Plateau: Controls on apparent enrichment factors, effect of vapor sources and implication for altimetry. Geochim Cosmochim Acta, 211: 10-27

Zhao C, Yu Z, Zhao Y, Ito E. 2009. Possible orographic and solar controls of Late Holocene centennial-scale moisture oscillations in the northeastern Tibetan Plateau. Geophys Res Lett, 36: L21705

Zhao C, Yu Z, Zhao Y, Ito E, Kodama K P, Chen F. 2010. Holocene millennial-scale climate variations documented by multiple lakelevel proxies in sediment cores from Hurleg Lake, Northwest China. J Paleolimnol, 44: 995-1008

Zhao Y, Yu Z, Chen F, Ito E, Zhao C. 2007. Holocene vegetation and climate history at Hurleg Lake in the Qaidam Basin, northwest China. Rev Palaeobot Palynology, 145: 275-288

Zhao Y, Yu Z, Chen F, Liu X, Ito E. 2008. Sensitive response of desert vegetation to moisture change based on a near-annual resolution pollen record from Gahai Lake in the Qaidam Basin, northwest China. Glob Planet Change, 62: 107-114

Zhao Y, Yu Z, Liu X, Zhao C, Chen F, Zhang K. 2010. Late holocene vegetation and climate oscillations in the Qaidam Basin of the northeastern Tibetan Plateau. Quat Res, 73: 59-69

Zhuang G, Brandon M T, Pagani M, Krishnan S. 2014. Leaf wax stable isotopes from Northern Tibetan Plateau: Implications for uplift and climate since 15 Ma. Earth Planet Sci Lett, 390: 186-198

(责任编委: 胡建芳) 